\title{
Overview of the biology of type I interferons
}

\author{
George D Kalliolias' and Lionel B Ivashkiv',2*
}

\begin{abstract}
Type I interferons are pleiotropic cytokines with antiviral, antitumor and immunoregulatory functions. An aspect of their complex biology is the paradox that, depending on context, type I interferons can be anti-inflammatory and tissue protective or can be proinflammatory and promote autoimmunity. Along these lines, the activation of type I interferon pathways is effective in suppressing disease activity in patients with multiple sclerosis and in animal models of arthritis and colitis, while there is an expectation that blockade of the same pathways will be beneficial in the treatment of patients with systemic lupus erythematosus.
\end{abstract}

\section{Introduction}

In 1957 a soluble product of influenza virus-infected chick embryo cells that conferred resistance to viral infection was first described [1]. During the following years a family of cytokines capable of interfering (inhibiting) with viral replication was discovered in jawed vertebrates, and its members were defined as interferons $[2,3]$. The family of interferons comprises type I interferons, the type II interferon named IFN $\gamma$ and the most recently discovered type III interferons, termed IFN $\lambda\left(\right.$ IFN $\lambda_{1}$ or IL-29, IFN $\lambda_{2}$ or IL-28A and IFN $\lambda_{3}$ or IL-28B) $[4,5]$. Type I interferons are a large group of structurally similar cytokines, in humans including more than 13 different members of IFN $\alpha$ as well as IFN $\beta$, IFN $\varepsilon$, IFNK and IFN $\omega$ [6]. The genes encoding type I interferons are clustered in one locus on the same chromosome (chromosome 9 in humans and chromosome 4 in mice), and they have been suggested to have diverged from a common ancestor, with the IFN $\beta$ gene being the primordial gene [7].

Today, more than 50 years after their discovery, type I interferons have been included in our therapeutic

\footnotetext{
*Correspondence: ivashkivl@hss.edu

'Arthritis and Tissue Degeneration Program and Department of Medicine, Hospital for Special Surgery, 535 East 70 th Street, Research Building $4^{\text {th }}$ floor, New York, NY 10021, USA

Full list of author information is available at the end of the article
}

armamentarium and are indicated for several disease entities $[2,8]$. Firstly, type I interferons are widely used for the treatment of chronic viral infections, mainly by hepatitis B virus and hepatitis C virus [2]. Several major breakthroughs in the field of interferon research have established the notion that type I interferons are not only antiviral peptides but pleiotropic cytokines. Along these lines it was observed that type I interferons can inhibit growth of some tumors by suppressing proliferation and inducing cell apoptosis, inhibiting angiogenesis, increasing immunogenicity of tumor cells and activating cytotoxicity against tumor cells [2]. In this context, $\mathrm{IFNa}_{2}$ is used in some treatment regimens for malignancies including chronic B-cell (hairy) leukemia, chronic myelogenous leukemia, myeloma, lymphomas, melanoma, renal-cell and bladder carcinoma and Kaposi's sarcoma $[2,8]$. Finally, recognition of modulatory effects of type I interferons has led to the discovery that they may successfully be applied in the treatment of multiple sclerosis (MS) [9]. Type I interferons have also been used in the treatment of rheumatoid arthritis (RA) and inflammatory bowel disease (IBD), with more success in animal models than in the clinic [10-21].

In addition to the above-described beneficial effects in infections, in malignancies and in some autoimmune/ inflammatory diseases, there is evidence that type I interferons can also be detrimental for the host by promoting autoimmunity, inflammation and interferontreatment-related toxicities in a context-dependent manner [1,2,22-25]. The present review serves as an updated summary of the prevailing concepts about the biology of type I interferons and also provides insights for a better understanding of the interferon paradox: type I interferons in one context promote autoimmunity and inflammation, but in another context have homeostatic functions by restraining inflammation and tissue destruction [14,26-28]. This paradox is exemplified by the opposing roles of type I interferons in systemic lupus erythematosus (SLE) (probably pathogenic) [22] and in MS (protective and therapeutic) [9].

\section{Type I interferon production in the context of infection, autoimmunity and inflammation}

Type I interferons are produced during infection as part of an effective host defense against pathogens [3]. Type I interferon production is triggered by pathogen-associated 
molecular patterns (mainly microbial nucleic acids and lipopolysaccharide) in the context of infections. In the setting of SLE, type I interferons are induced by immune complexes containing self-derived nucleic acids [3,7,22]. Serum levels of type I interferons have been observed in patients with active SLE, and this endogenous type I interferon is believed to contribute to pathogenesis [29]. Interestingly, IFN $\beta$ is expressed in the inflamed synovium of patients with RA and at sites of central nervous system inflammation in experimental autoimmune encephalomyelitis (EAE) [30,31]. This low level of local interferon is suspected to represent activation of a homeostatic mechanism to control the intensity of inflammation and to restrain the extent of tissue destruction $[14,32]$. Inflammatory stimuli (including the cytokines TNF $\alpha$ and RANKL) produced in the microenvironment of the synovium and central nervous system may contribute to the local expression of type I interferons during RA and EAE $[33,34]$.

Indispensable for induction of expression of type I interferons is the balanced activation of several transcription factors, including interferon regulatory factors (IRFs), NF-kB and AP-1 [7]. IRFs are considered key transcription factors for induction of type I interferons. They are activated by kinases in a cell-type-specific and stimulus-specific manner. IRF-3 is constitutively expressed and, following activation, potently activates the IFN $\beta$ gene. IRF-7 is highly expressed in plasmacytoid dendritic cells (DCs) and is induced by type I interferons; it efficiently activates both IFN $\alpha$ and IFN $\beta$ genes, and can serve as part of an amplification loop to augment type I interferon production [35]. IRF-1 has been implicated in low-level induction of IFN $\beta$ by TNF $\alpha$ [33]. Evidence indicates that certain IRF-5 mutations, by regulating interferon type I activity, confer susceptibility to SLE [36, 37]. Finally, c-Fos, the partner of c-Jun in the transcription factor AP-1, drives production of IFN $\beta$ downstream of RANKL signaling [34].

In the setting of infection, recognition of pathogenderived nucleic acids by specific sensors within the host's cells is a major stimulus for the production of type I interferons (Figure 1) [3,7]. According to a recent report, binding of the nucleic acids to high-mobility group box (HMGB) proteins is required for their efficient recognition by the host's sensors [38]. Two intracellular systems account for sensing nucleic acids that induce type I interferons: one is Toll-like receptor (TLR) dependent and is restricted to endosomes of specialized sentinel cells (monocytes, macrophages and DCs); the other is cytosolic and is ubiquitously expressed [3,7].

The TLR-dependent interferon-inducing system comprises TLR3, TLR7/8 and TLR9, which specifically sense dsRNA, ssRNA and DNA (hypomethylated CpG DNA), respectively. The cytosolic sensing system includes the

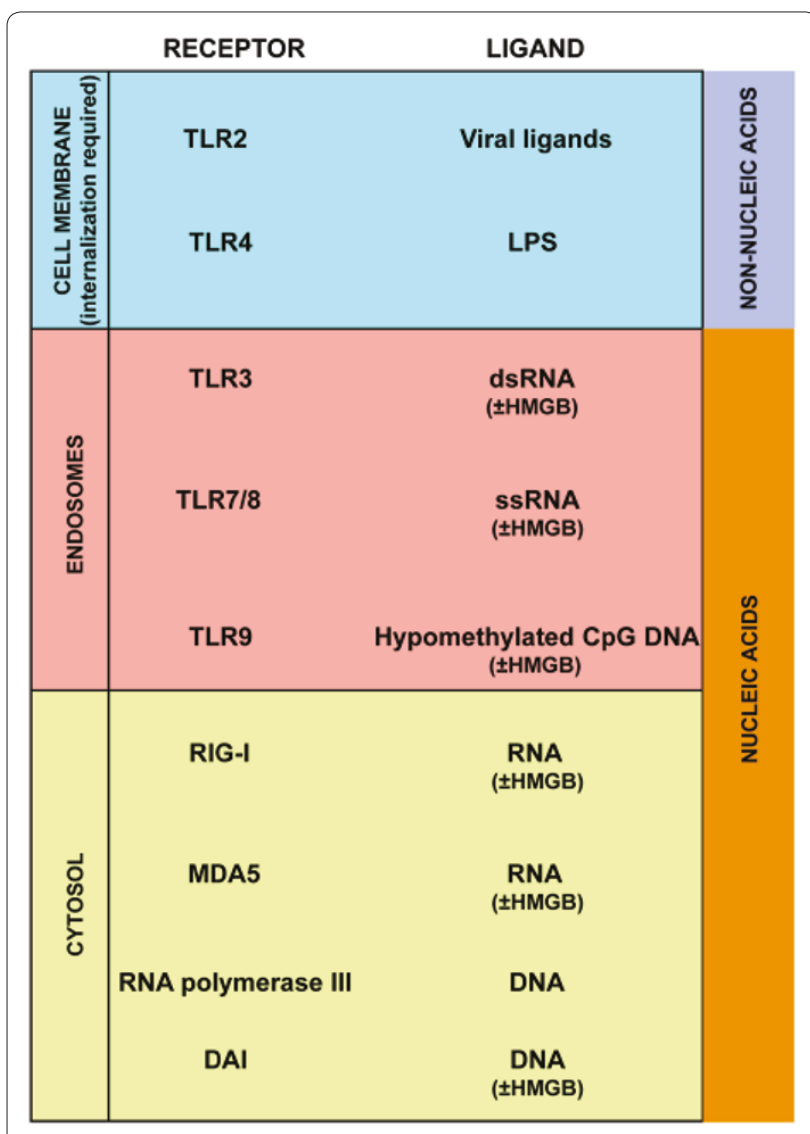

Figure 1. Pathways (receptors and ligands) leading to type I interferon production. DAl, DNA-dependent activator of interferon regulatory factors; $H M G B$, high-mobility group box protein; LPS, lipopolysaccharide; MDA5, melanoma differentiation-associated protein 5; RIG-I, retinoic acid inducible gene I; TLR, Toll-like receptor.

retinoic acid inducible gene (RIG)-like receptors RIG-I and melanoma differentiation-associated protein 5 (MDA5), which are sensors of cytosolic RNA [7], the DNA-sensing receptor DAI (DNA-dependent activator of IRFs) [39], and RNA polymerase III, which transcribes cytosolic DNA into RNA that is sensed by RIG-like receptors $[40,41]$. In general, the binding of the endosomal or cytosolic receptors with the high-mobility group boxnucleic acid complexes leads to recruitment of adaptor molecules (TRIF/TRAF3/NAP1 for TLR3, MyD88 for TRL7/8 and TLR9, and IPS1/TRAF3 for RIG-I and MDA5). In a cell-type-specific and stimulus-specific manner, kinases (TBK1, IRAK1, IKK $\alpha$, IKK $\varepsilon$ and phosphoinositide 3-kinase (PI3K)) are then recruited that phosphorylate serine and threonine residues on the latent IRFs. Activated IRFs form homodimers or heterodimers, translocate to the nucleus and bind to regulatory elements in the promoter regions of type I interferon genes, triggering transcription [7]. Although any nucleated cell has the capacity to produce type I interferons upon appropriate stimulation, prolonged endosomal retention 
of nucleic acids and high constitutive expression of TLR7, TLR9 and IRF-7 render plasmacytoid DCs the most powerful producers of type I interferons [7].

Type I interferon production can also be induced by non-nucleic acid pathogen-derived molecular patterns (Figure 1). Recognition of lipopolysaccharide by TLR4 triggers the activation of IRF-3 by TBK1 kinase and results in production of IFN $\beta$ [42]. This pathway is dependent on recruitment to the intracellular domain of TLR4 of the adaptor molecules TRAM, TRIF, TRAF3 and NAP1. It has recently been reported that TLR2 ligands of viral origin, but not those of bacterial origin, induce type I interferons in a MyD88/IRF-3/IRF-7dependent manner [43]. Trafficking of TLR2 and TLR4 from the plasma membrane to the endosomal compartment is required for induction of type I interferon $[42,43]$. Interestingly, monocytes are a key source of TLR2-induced type I interferons in vitro and in vivo [43]. Since monocytic cells outnumber plasmacytoid DCs in vivo, the latter may not be the major source of type I interferons in vivo. Indeed, monocytic cells have been identified as the major source of type I interferons in animal models of infection [44] and of lupus [45].

In SLE, excess apoptosis and tissue damage combined with decreased clearance of apoptotic bodies probably result in an increased load of immunogenic self-nucleic acid-containing particles [22]. Circulating autoantibodies, specific for nucleic acids or nucleoproteins, form immune complexes with the particles. These complexes are captured by receptors - for example, Fc $\gamma$ RIIa - expressed on the surface of sentinel cells (monocytes, macrophages and DCs), gain access to the intracellular compartment, and are recognized by the endosomal and cytosolic system that trigger type I interferon production [22].

\section{Signaling pathways of type I interferons: not only Jak-STAT}

The pleiotropic functions of type I interferons mirror a complexity of intracellular signaling pathways [6]. The type I interferons all utilize a ubiquitously expressed heterodimeric IFN $\alpha / \beta$ receptor (IFNAR) and generate similar, although not necessarily identical, signals [4].

IFNAR consists of IFNAR1 and IFNAR2 subunits that are associated with cytoplasmic protein tyrosine kinases Tyk2 and Jak1, respectively. IFNAR2 is also constitutively associated with STAT2. Ligation of IFNAR results in activation of Tyk2 and Jak1, and in phosphorylation of tyrosine residues in the IFNAR cytoplasmic domains, thus creating docking sites for signal transducers and activators of transcription (STATs), including STAT2 and proabably STAT1. Both STAT1 and STAT2 are activated at the IFNAR signaling complex by tyrosine phosphorylation, with subsequent formation of STAT1:STAT2 heterodimers and STAT1:STAT1 homodimers [46].
These STAT proteins translocate to the nucleus, where STAT1:STAT1 homodimers bind to gamma-activated sequence (GAS) sites (consensus sequence TTCNNNGAA) in gene promoters and activate transcription. In contrast, STAT1:STAT2 heterodimers associate with IRF9 to form the ISGF3 complex that binds to an interferon-stimulated response element (ISRE) site (consensus sequence TTTCNNTTTC) [4,46]. Type I interferons thus activate expression of genes that have either GAS or ISRE sites, or both, in their promoters $[2,46,47]$. ISGF3 and cognate interferon-stimulated response elements play a key role in activation of antiviral genes and antiviral responses, whereas gamma-activated sequence elements mediate induction of inflammatory genes such as chemokines. Type I interferons can also activate STAT3 and, in a celltype-specific manner, STAT4, STAT5 and STAT6 [47].

In addition to the classical Jak-STAT pathway, other signaling pathways - including the mitogen-activated protein kinase pathways and the PI3K pathways - are activated by type I interferons [6]. These nonclassical signaling pathways are activated in a stimulus-specific and cell-type-specific manner downstream of IFNAR. There is evidence that the cytoplasmic protein tyrosine kinases Tyk2 and Jak1 are actively implicated in the induction of the nonclassical signaling pathways. For example, they phosphorylate the insulin receptor substrates 1 and 2, providing a docking site for the regulatory domain of PI3K (p85), and they activate upstream regulators of $\mathrm{p} 38$, triggering activation of the PI3K and p38 pathways, respectively. The biologic consequences of the activation of these nonclassical signaling pathways have been reviewed recently [6].

\section{Type I interferons as boosters of immune responses: implication in SLE pathogenesis}

Type I interferons are constitutively expressed at low levels; expression is rapidly enhanced upon viral or bacterial infection, aiming for an effective immune response against the pathogens $[3,35]$. Type I interferons induce an antiviral state in cells by suppressing mechanisms for viral replication, trigger apoptosis in virally infected cells, promote natural killer cell-mediated and $\mathrm{CD} 8^{+} \mathrm{T}$-cellmediated cytotoxicity, promote the transition from innate to acquired immunity by augmenting DC maturation, cross-presentation of antigens and migration, and enhance T-helper type 1 responses, generation of $\mathrm{T}$ follicular helper cells, and humoral responses [3,8,48-51].

Mounting observations indicate that type I interferons are implicated in the pathogenesis of several diseases, with autoimmune characteristics including SLE, primary Sjögren's syndrome, dermatomyositis, scleroderma and insulin-dependent diabetes mellitus [24]. The role of type I interferons in SLE pathogenesis is now a well-established notion that has been supported by several lines of 
evidence derived from humans and animal models. Serum levels of IFNo in SLE patients can be as high as levels achieved during acute viral infections, and a positive correlation between serum IFN $\alpha$ levels and disease severity has been described [29,52]. Additionally, gene expression profiling with microarrays and real-time PCR demonstrated an IFN $\alpha$ signature in peripheral blood cells of SLE patients that was correlated with disease activity $[53,54]$. Interestingly, IFN $\alpha$ therapy in the setting of cancer or chronic viral infection induces autoantibody formation in 4 to $19 \%$ of patients and occasionally induces SLE-like symptoms [22,25]. Finally, IFN $\alpha$ administration in lupus-prone mice accelerates disease, and deletion of IFNAR substantially decreases morbidity and prolongs survival in these animals $[24,55]$. SLE is characterized by autoimmunity and organ inflammation. Type I interferons may contribute to disease pathogenesis by promoting either autoimmunity or inflammation, or both (Figure 2, left-hand side) $[22,23,46]$.

One mechanism by which type I interferons may promote autoimmunity, driving SLE pathogenesis, consists of abrogating peripheral tolerance to autoantigens through activation of immature DCs [22]. Normally, autoreactive lymphocytes that have escaped from the central checkpoint of the thymus are controlled in the periphery by immature DCs lacking co-stimulatory molecules. DCs capture, process and present antigens in association with MHC molecules to lymphocytes. Antigen presentation by immature DCs leads to tolerance. Type I interferons promote maturation of DCs through induction of MHC II molecules, as well as CD40, CD80 and CD86 co-stimulatory molecules. Sera from patients with active SLE promote in vitro maturation of DCs, and blood monocytes derived from these patients exhibit DC-like properties such as enhanced antigen presentation and co-stimulatory capacity [29]. During the course of SLE, tissue damage and decreased clearance of apoptotic bodies generate an excess of autoantigens. Augmented levels of type I interferons may promote a break of tolerance to these autoantigens, thus driving autoimmunity (by allowing activation of autoreactive lymphocytes by interferon-activated DCs) [22].

A hallmark of SLE is the presence of autoantibodies, including antinuclear antibodies, antibodies directed to cell surface molecules (on erythrocytes, platelets, neurons), antibodies against proteins bound to phospholipids and antibodies against antigens expressed in target organs like the kidney [22]. Type I interferons, via complex mechanisms, enhance antibody responses (adjuvant activity) and promote long-term antibody production, class switching and immunological memory [48-51]. Recently it has been reported that type I interferons stimulate generation of germinal centers by targeting DCs and stromal cells to promote development of $\mathrm{T}$ follicular helper cells [48]. The $\mathrm{T}$ follicular helper cells represent a distinct T-helper cell population restricted to draining lymph nodes and specialized in supporting differentiation of germinal center B cells, a mandatory process for production of class-switched IgG [48]. Additionally, type I interferons stimulate production of B-cell activating factor belonging to the TNF family (BAFF), of a proliferation-inducing ligand (APRIL), and of IL-6 - all of which promote B-cell survival and differentiation to plasmablasts and antibody-producing plasma cells $[22,50]$.

Several investigators, including our group, have considered the possibility that type I interferons may contribute to SLE pathogenesis by bolstering inflammatory responses through priming of myeloid cells (DCs and macrophages) and by inducing high-level STAT1 expression [46]. The concept of priming is a key aspect of interferon biology and is defined as pre-exposure to low concentrations of interferons leading to enhanced responses to minor subsequent stimuli (including infections, autoantigens, environmental antigens, components of damaged tissues, or cytokines) [35]. The classical function of priming is to potentiate innate immune responses during the early phase of infections when cytokine concentrations are low, thereby enhancing host defense. A common theme is that priming results in increased activation of STAT1, with its attendant inflammatory actions. STAT1 further amplifies cell activation by activating STAT1-mediated feedforward mechanisms (described below) and by counteracting feedback pathways such as those mediated by suppressor of cytokine signaling (SOCS) proteins or STAT3 [46].

A substantial body of data supports the notion that priming of immunocytes occurs in SLE and other rheumatic diseases and contributes to disease pathogenesis. As previously noted, type I interferons are expressed in SLE at levels that would be expected to elicit priming [29]. Furthermore, leukocytes isolated from SLE patients have been found to express increased levels of STAT1, a key marker in interferon priming. Interestingly, with the use of corticosteroids, suppression of STAT1 expression occurs concomitantly with demonstrated clinical improvement in SLE patients, thereby providing a possible mechanism of action for this drug class in systemic lupus [23]. Isolated monocytes of SLE patients who had not undergone treatment displayed an enhanced response to TLR activators (such as lipopolysaccharide) and IL-1 $\beta$, potentially as a result of in vivo interferonmediated priming [46]. By priming the host response, type I interferons can, in turn, enhance and modulate the inflammatory cellular responses to other molecules long implicated in modulating the pathogenesis of autoimmune diseases, such as TNF, IL- 1 and IL-6, IFN $\gamma$, and TLRs $[23,35,46,47]$. 
Several mechanisms have been proposed to explain how exposure to interferons sensitizes cells to subsequent stimuli. Stimulation with type I interferons potentiates the physical association between IFNAR1 and IFNGR2 or gp130 [35]. Formation of such receptor complexes (receptosomes) increases the docking sites for STATs, resulting in more efficient dimerization of these STATs and enhanced responses to IFNY and IL-6. Another mechanism of priming with relevance to SLE is that type I interferons induce increased expression of TLR3, TLR7 and TLR9, thus sensitizing cells to nucleic acid stimulation. As previously noted, a key feature of interferon priming is the increased expression of STAT1 [56]. Increased intracellular availability of STAT1 results in increased STAT1 phosphorylation downstream of IFNGR and IL- 6 receptors, resulting in enhanced cellular activation in response to IFNY and IL-6 stimulation $[46,47,57]$. An additional aspect of the biological consequences of the high intracellular levels of STAT1 is the perturbation of IL-10 signaling and function. IL-10, a powerful anti-inflammatory cytokine, is a potent activator of the anti-inflammatory STAT3 and a weak activator of STAT1 in myeloid cells, and does not normally induce STAT1 target genes as does IFNץ. Pre-exposure to type I interferons, however, reprograms STAT activation by IL10 such that STAT1 is more strongly activated by IL-10 in these cells, resulting in induction of a group of STAT1dependent genes and thereby a gain of inflammatory function [56].

Additional mechanisms by which type I interferons may promote inflammation and tissue damage in the context of SLE include the induction of pathogenic complement-fixing antibodies and production of chemokines that recruit inflammatory cells at sites of immune complex deposition [23]. It is also interesting to consider the possibility that type I interferons may have pathogenic effects by acting on cells in target organs. Recent evidence from our and other laboratories has demonstrated an interferon signature in the kidneys in murine lupus nephritis that is associated with macrophage infiltration and proliferative nephritis $[58,59]$. Our study provides in vivo evidence that IFN $\alpha$ increases matrix metalloproteinase activation and growth factor expression to promote glomerular cell proliferation and early fibrosis. This process was mediated by alternatively activated macrophages expressing a dysregulated tissue repair program [58].

\section{A role for type I interferons in attenuation of inflammation and tissue destruction}

Although an interferon signature has been observed in peripheral blood cells derived from a subgroup of patients with MS and active RA [60-62], there is evidence suggesting that type I interferons are therapeutic in MS and are potentially beneficial for RA and IBD by reining inflammation and tissue destruction. Firstly, IFN $\beta$ has been shown to reduce attack frequency in patients with MS and has become the established treatment of choice for the relapsing remitting form of MS [9]. Additionally, in animal models of inflammatory arthritis, MS (EAE) and IBD, administration or triggered production of IFN $\alpha / \beta$ or IFN $\beta$ gene therapy has been shown to reduce disease severity $[10,11,13,15,16,20,63,64]$, while the lack of type I interferon signaling (IFNAR1 knockout or IFN $\beta$ knockout) resulted in more severe disease manifestation $[15,16,20,31,65,66]$.

Various mechanisms have been proposed to explain such anti-inflammatory and tissue-protective effects of type I interferons (Figure 2, right-hand side) [14,26-28]. Reports suggest that type I interferons regulate the inflammatory milieu by increasing expression of antiinflammatory factors (including IL-10, IL-27, transforming growth factor beta, IL-1R antagonist, soluble TNF receptors, suppressor of cytokine signaling) and decreasing proinflammatory mediators (including IL-1, IL-6, IL-8, IL-12, IL-18, TNF $\alpha$, IFN $\gamma$, osteopontin, prostaglandin $\mathrm{E}$ and cyclooxygenase-2) [8,14,26,28,67]. It is important to emphasize that type I interferons modulate the inflammatory microenvironment in a contextdependent manner and not uniformly. Thus, administration of IFN- $\beta$ in mice with collagen-induced arthritis resulted in significant decrease in synovial expression of TNF- $\alpha$ and IL-6 [13], while in rats with adjuvant-induced arthritis expression of IL- $1 \beta$ but not TNF- $\alpha$ and IL- 6 was reduced [64].

Type I interferons suppress production of proinflammatory cytokines both at the level of transcription and at the level of mRNA stability. One mechanism may be the capacity of type I interferons to suppress key transcription factors for induction of proinflammatory cytokines (including NF-kB, AP-1 and PU.1) [13,23]. In a study from our laboratory, IFN $\alpha$ also suppressed TNF $\alpha$ production by inducing expression of the tyrosine kinase Axl that in turn induced expression of Twist, a transcriptional repressor of the TNF $\alpha$ promoter [68]. Interferon-induced Axl and related TAM kinases have been implicated in feedback suppression of TLR responses by a SOCS1-mediated mechanism [69]. Additionally, type I interferons induce the expression of an RNA-binding protein named tristetraprolin, which destabilizes transcripts of proinflammatory cytokines (including TNF $\alpha$ and IL-6) by mediating mRNA decay [70].

Evidence also indicates that type I interferons not only suppress production but also inhibit the function of proinflammatory mediators. Our group observed, using an in vitro system, that IFN $\alpha$ attenuates IL- $1 \beta$ proinflammatory effects by downregulating the expression of the signaling receptor IL-1RI [71], and others have found that 


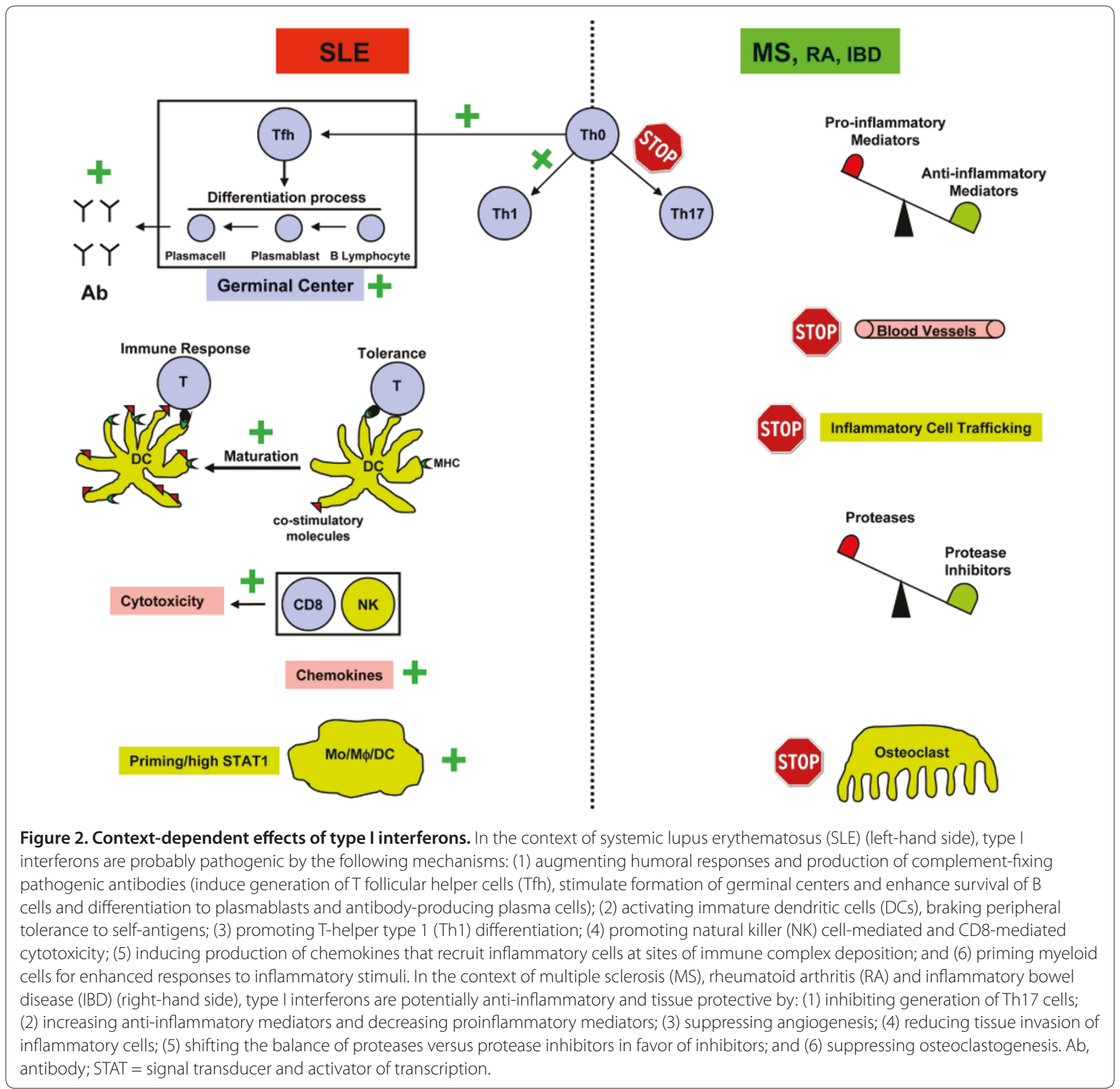

type I interferons induce production of IL-1R antagonist by a PI3K-mediated mechanism [72].

Interestingly, accumulating evidence indicates that type I interferons suppress T-helper type 17 (Th17) cell development $[66,67,73-75]$. In animal models of arthritis (collagen-induced arthritis) and central nervous system inflammation (EAE), Th17 cells are principal drivers for disease pathogenesis. Their pathogenic role has also been suspected in human diseases including RA, MS, IBD, psoriasis, juvenile diabetes and autoimmune uveitis. It has been suggested that type I interferons suppress Th17 cell generation by modulating the cytokine microenvironment that determines the fate of T-helper cells.
Type I interferons - by targeting antigen-presenting cells (monocytes, macrophages and DCs) - increase the production of IL-27, which is a potent inhibitor of Th17, and decrease IL- $1 \beta$, transforming growth factor beta 1 and IL-23, which favor Th17 differentiation $[66,67,74,75]$. A recent report indicates that type I interferons induce the production of IL-27 in DCs by downregulating the intracellular isoform of osteopontin (Opn-i) [67].

The anti-angiogenic effect of type I interferons may represent another mechanism contributing to the beneficial function of type I interferons in the context of inflammatory arthritis, where increased vascularization is a prominent component of synovial pathology [14]. 
Type I interferons inhibit angiogenesis either indirectly by targeting nonendothelial cells or directly by targeting endothelial cells. In nonendothelial cells, type I interferons decrease the production of angiogenesis-promoting factors (including basic fibroblast growth factor and vascular endothelial growth factor) and induce angiostatic chemokines [14]; in endothelial cells, type I interferons trigger an antiangiogenic program of gene expression [76] and suppress proliferation of endothelial cells and their progenitors [77].

Another important facet of the homeostatic function of type I interferons is their capacity to protect tissue integrity and restrain damage. IFN $\beta$ preserves the integrity of the blood-brain barrier and attenuates demyelination in EAE [31,32], and prevents destruction of cartilage and bone in animal models of arthritis [14]. Proposed explanations for this tissue protection have been that type I interferons regulate inflammatory cell trafficking, modulate the balance between proteases and protease inhibitors and inhibit osteoclastogenesis $[14,26,28]$. Type I interferons restrict tissue invasion of inflammatory cells by regulating the expression of adhesion molecules (downregulate expression on the cell surface and upregulate soluble forms of adhesion molecules) and by reducing MMP-9, which degrades extracellular matrix and facilitates tissue entrance of inflammatory cells [14]. Finally, type I interferons are powerful inhibitors of osteoclastogenesis by decreasing expression of c-Fos, an essential transcription factor required for osteoclastogenesis induced downstream of RANKL [34]. Additional mechanisms that contribute to the anti-osteoclastogenic effects of type I interferon may include an inhibitory effect on the expression of osteoclastogenic TNF $\alpha$ and IL-1 $\beta$ and decreased c-Cbl and Cbl-b expression [64].

\section{Concluding remarks}

It is clear that type I interferons can either promote or suppress immune and inflammatory responses and autoimmune diseases, depending on the context (Figure 2). Several explanations for the pleiotropic and paradoxical nature of interferon activity in different immune responses and autoimmune diseases have been proposed. These include different biological activities based on timing, different concentration-dependent effects, the location of expression and effects on cells that make up target organs, and differential effects on immunity versus inflammation or on innate immunity versus acquired immunity $[46,47]$. In addition, type I interferon activity and signaling are regulated and reprogrammed during immune and inflammatory responses, with alterations in the balance between activation of STAT1 and STAT3 or STAT4 [78,79]. An alternative nonmutually exclusive explanation proposes an interferon-TNF axis in which each cytokine is pathogenic in different diseases and in which interferons and TNF cross-inhibit each other's expression [22]. Emerging evidence supports a complex crossregulation between interferons and TNF, including induction of interferons by TNF in certain cell types [33] and extensive crosstalk at the level of signal transduction.

Blockade of type I interferon pathways has emerged as an attractive therapeutic approach for SLE [22,24], while activation of the same pathways has proven clinically effective in a subset of patients with MS [9] and in animal models of RA and IBD $[14,20]$. This distinction reflects an interferon paradox and raises the question of how we can target interferon pathways (block or trigger) in such a way that detrimental effects are minimized while beneficial effects, including a key role in antiviral host defense, are preserved. Therapeutic approaches that target specific interferon-induced signaling pathways may be beneficial. For example, selective inhibition of proinflammatory STAT1 activation while preserving ISGF3 activation and antiviral responses may represent a fruitful approach [78]. A better understanding and characterization of the molecular mechanisms that regulate type I interferon signaling and downstream target genes (for example, by applying bioinformatics) will set the stage for selective manipulation of interferon pathways without the risk of compromising homeostatic functions or host defense.

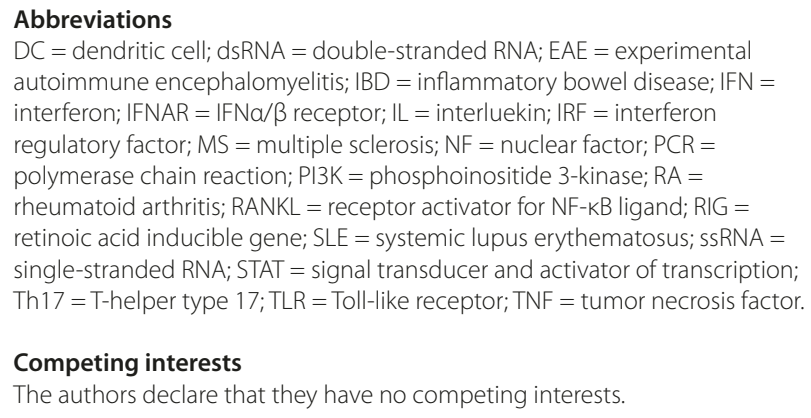

This article is part of Arthritis Research \& Therapy Volume 12 Supplement 1: The role of IFN alpha in autoimmune disease. The full contents of the supplement are available online at http://arthritis-research.com/supplements/12/S1. Publication of the supplement has been supported with funding from Medlmmune, LLC.

\section{Author details}

'Arthritis and Tissue Degeneration Program and Department of Medicine, Hospital for Special Surgery, 535 East 70 $0^{\text {th }}$ Street, Research Building $4^{\text {th }}$ floor, New York, NY 10021, USA. ${ }^{2}$ Graduate Program in Immunology and Microbial Pathogenesis, Weill Cornell Graduate School of Medical Sciences, New York, NY 10021, USA.

Published: 14 April 2010
References
1. Vilcek J: Fifty years of interferon research: aiming at a moving target. Immunity 2006, 25:343-348. 
2. Borden EC, Sen GC, Uze G, Silverman RH, Ransohoff RM, Foster GR, Stark GR: Interferons at age 50: past, current and future impact on biomedicine. Nat Rev Drug Discov 2007, 6:975-990

3. Stetson DB, Medzhitov R: Type I interferons in host defense. Immunity 2006, 25:373-381

4. Stark GR, Kerr IM, Williams BR, Silverman RH, Schreiber RD: How cells respond to interferons. Annu Rev Biochem 1998, 67:227-264.

5. Li M, Liu X, Zhou Y, Su SB: Interferon-lambdas: the modulators of antivirus, antitumor, and immune responses. J Leukoc Biol 2009, 86:23-32.

6. Platanias LC: Mechanisms of type-I- and type-II-interferon-mediated signalling. Nat Rev Immuno/ 2005, 5:375-386.

7. Honda K, Takaoka A, Taniguchi T: Type I interferon [corrected] gene induction by the interferon regulatory factor family of transcription factors. Immunity 2006, 25:349-360

8. Brassard DL, Grace MJ, Bordens RW: Interferon-alpha as an immunotherapeutic protein. J Leukoc Bio/ 2002, 71:565-581.

9. Buttmann $M$, Rieckmann P: Interferon- $\beta 1 \mathrm{~b}$ in multiple sclerosis. Expert Rev Neurother 2007. 7:227-239

10. Triantaphyllopoulos KA, Williams RO, Tailor H, Chernajovsky Y: Amelioration of collagen-induced arthritis and suppression of interferon-gamma, interleukin-12, and tumor necrosis factor alpha production by interferonbeta gene therapy. Arthritis Rheum 1999, 42:90-99.

11. Tak PP, Hart BA, Kraan MC, Jonker M, Smeets TJ, Breedveld FC: The effects of interferon beta treatment on arthritis. Rheumatology (Oxford) 1999, 38:362-369.

12. van Holten J, Plater-Zyberk C, Tak PP: Interferon-beta for treatment of rheumatoid arthritis? Arthritis Res 2002, 4:346-352.

13. van Holten J, Reedquist K, Sattonet-Roche P, Smeets TJ, Plater-Zyberk C, Vervoordeldonk MJ, Tak PP: Treatment with recombinant interferon-beta reduces inflammation and slows cartilage destruction in the collageninduced arthritis model of rheumatoid arthritis. Arthritis Res Ther 2004 6:R239-R249.

14. Tak PP: IFN-beta in rheumatoid arthritis. Front Biosci 2004, 9:3242-3247.

15. Yarilina A, DiCarlo E, Ivashkiv LB: Suppression of the effector phase of inflammatory arthritis by double-stranded RNA is mediated by type I IFNs. J Immunol 2007, 178:2204-2211.

16. Corr M, Boyle DL, Ronacher L, Flores N, Firestein GS: Synergistic benefit in inflammatory arthritis by targeting IKB kinase epsilon and interferon beta. Ann Rheum Dis 2009, 68:257-263.

17. Vervoordeldonk MJ, Aalbers CJ, Tak PP: Interferon beta for rheumatoid arthritis: new clothes for an old kid on the block. Ann Rheum Dis 2009 68:157-158.

18. Genovese MC, Chakravarty EF, Krishnan E, Moreland LW: A randomized, controlled trial of interferon-beta-1a (Avonex(R)) in patients with rheumatoid arthritis: a pilot study [ISRCTN03626626]. Arthritis Res Ther 2004, 6:R73-R77.

19. van Holten J, Pavelka K, Vencovsky J, Stahl H, Rozman B, Genovese M, Kivitz AJ, Alvaro J, Nuki G, Furst DE, Herrero-Beaumont G, McInnes IB, Musikic P, Tak PP: A multicentre, randomised, double blind, placebo controlled phase II study of subcutaneous interferon beta-1a in the treatment of patients with active rheumatoid arthritis. Ann Rheum Dis 2005, 64:64-69.

20. Katakura K, Lee J, Rachmilewitz D, Li G, Eckmann L, Raz E: Toll-like receptor 9-induced type I IFN protects mice from experimental colitis. J Clin Invest 2005, 115:695-702.

21. Seow CH, Benchimol El, Griffiths AM, Steinhart AH: Type I interferons for induction of remission in ulcerative colitis. Cochrane Database Syst Rev 2008, 3:CD006790.

22. Banchereau J, Pascual V: Type I interferon in systemic lupus erythematosus and other autoimmune diseases. Immunity 2006, 25:383-392.

23. Ivashkiv LB: Type I interferon modulation of cellular responses to cytokines and infectious pathogens: potential role in SLE pathogenesis. Autoimmunity 2003, 36:473-479.

24. Theofilopoulos AN, Baccala R, Beutler B, Kono DH: Type I interferons (alpha/ beta) in immunity and autoimmunity. Annu Rev Immuno/ 2005, 23:307-336.

25. Gota C, Calabrese L: Induction of clinical autoimmune disease by therapeutic interferon-alpha. Autoimmunity 2003, 36:511-518.

26. Billiau A: Anti-inflammatory properties of Type I interferons. Antiviral Res 2006, 71:108-116.

27. Biron CA: Interferons alpha and beta as immune regulators - a new look. Immunity 2001, 14:661-664.

28. Benveniste EN, Qin H: Type I interferons as anti-inflammatory mediators. Sci
SCiSTKE 2007, 2007(416):pe70

29. Blanco P, Palucka AK, Gill M, Pascual V, Banchereau J: Induction of dendritic cell differentiation by IFN-alpha in systemic lupus erythematosus. Science 2001, 294:1540-1543.

30. van Holten J, Smeets TJ, Blankert P, Tak PP: Expression of interferon beta in synovial tissue from patients with rheumatoid arthritis: comparison with patients with osteoarthritis and reactive arthritis. Ann Rheum Dis 2005, 64:1780-1782

31. Prinz M, Schmidt H, Mildner A, Knobeloch KP, Hanisch UK, Raasch J, Merkler D, Detje C, Gutcher I, Mages J, Lang R, Martin R, Gold R, Becher B, BrückW, Kalinke $U$ : Distinct and nonredundant in vivo functions of IFNAR on myeloid cells limit autoimmunity in the central nervous system. Immunity 2008, 28:675-686.

32. Axtell RC, Steinman L: Type 1 interferons cool the inflamed brain. Immunity 2008, 28:600-602.

33. Yarilina A, Park-Min KH, Antoniv T, Hu X, Ivashkiv LB: TNF activates an IRF1dependent autocrine loop leading to sustained expression of chemokines and STAT1-dependent type I interferon-response genes. Nat Immunol 2008, 9:378-387.

34. Takayanagi H, Kim S, Matsuo K, Suzuki H, Suzuki T, Sato K, Yokochi T, Oda H, Nakamura K, Ida N, Wagner EF, Taniguchi T: RANKL maintains bone homeostasis through c-Fos-dependent induction of interferon-beta. Nature 2002, 416:744-749.

35. Taniguchi T, Takaoka A: A weak signal for strong responses: interferonalpha/beta revisited. Nat Rev Mol Cell Biol 2001, 2:378-386.

36. Kozyrev SV, Alarcon-Riquelme ME: The genetics and biology of Irf5mediated signaling in lupus. Autoimmunity 2007, 40:591-601.

37. Niewold TB, Kelly JA, Flesch MH, Espinoza LR, Harley JB, Crow MK: Association of the IRF5 risk haplotype with high serum interferon-alpha activity in systemic lupus erythematosus patients. Arthritis Rheum 2008, 58:2481-2487.

38. Yanai H, Ban T, Wang Z, Choi MK, Kawamura T, Negishi H, Nakasato M, Lu Y, Hangai S, Koshiba R, Savitsky D, Ronfani L, Akira S, Bianchi ME, Honda K, Tamura T, Kodama T, Taniguchi T: HMGB proteins function as universal sentinels for nucleic-acid-mediated innate immune responses. Nature 2009, 462:99-103.

39. Takaoka A, Wang Z, Choi MK, Yanai H, Negishi H, Ban T, Lu Y, Miyagishi M, Kodama T, Honda K, Ohba Y, Taniguchi T: DAI (DLM-1/ZBP1) is a cytosolic DNA sensor and an activator of innate immune response. Nature 2007, 448:501-505.

40. Chiu YH, Macmillan JB, Chen ZJ: RNA polymerase III detects cytosolic DNA and induces type I interferons through the RIG-I pathway. Cell 2009, 138:576-591

41. Ablasser A, Bauernfeind F, Hartmann G, Latz E, Fitzgerald KA, Hornung V: RIG-I-dependent sensing of poly (dA:dT) through the induction of an RNA polymerase III-transcribed RNA intermediate. Nat Immunol 2009, 10:1065-1072

42. Kagan JC, Su T, Horng T, Chow A, Akira S, Medzhitov R: TRAM couples endocytosis of Toll-like receptor 4 to the induction of interferon-beta. Nat Immunol 2008, 9:361-368.

43. Barbalat R, Lau L, Locksley RM, Barton GM: Toll-like receptor 2 on inflammatory monocytes induces type I interferon in response to viral but not bacterial ligands. Nat Immunol 2009, 10:1200-1207.

44. Kumagai Y, Takeuchi O, Kato H, Kumar H, Matsui K, Morii E, Aozasa K, Kawai T, Akira S: Alveolar macrophages are the primary interferon-alpha producer in pulmonary infection with RNA viruses. Immunity 2007, 27:240-252.

45. Lee PY, Weinstein JS, Nacionales DC, Scumpia PO, Li Y, Butfiloski E, van Rooijen N, Moldawer L, Satoh M, Reeves WH: A novel type I IFN-producing cell subset in murine lupus. J Immunol 2008, 180:5101-5108.

46. Hu X, Chakravarty SD, Ivashkiv LB: Regulation of interferon and Toll-like receptor signaling during macrophage activation by opposing feedforward and feedback inhibition mechanisms. Immunol Rev 2008 , 226:41-56.

47. van Boxel-Dezaire AH, Rani MR, Stark GR: Complex modulation of cell typespecific signaling in response to type I interferons. Immunity 2006 25:361-372.

48. Cucak H, Yrlid U, Reizis B, Kalinke U, Johansson-Lindbom B: Type I interferon signaling in dendritic cells stimulates the development of lymph-noderesident T follicular helper cells. Immunity 2009, 31:491-501.

49. Le Bon A, Schiavoni G, D'Agostino G, Gresser I, Belardelli F, Tough DF: Type I interferons potently enhance humoral immunity and can promote isotype switching by stimulating dendritic cells in vivo. Immunity 2001, 
$14: 461-470$

50. Jego G, Palucka AK, Blanck JP, Chalouni C, Pascual V, Banchereau J: Plasmacytoid dendritic cells induce plasma cell differentiation through type I interferon and interleukin 6. Immunity 2003, 19:225-234.

51. Le Bon A, Thompson C, Kamphuis E, Durand V, Rossmann C, Kalinke U, Tough DF: Cutting edge: enhancement of antibody responses through direct stimulation of B and T cells by type I IFN. J Immunol 2006, 176:2074-2078.

52. Kirou KA, Lee C, George S, Louca K, Peterson MG, Crow MK: Activation of the interferon-alpha pathway identifies a subgroup of systemic lupus erythematosus patients with distinct serologic features and active disease. Arthritis Rheum 2005, 52:1491-1503.

53. Crow MK, Kirou KA, Wohlgemuth J: Microarray analysis of interferonregulated genes in SLE. Autoimmunity 2003, 36:481-490.

54. Bennett L, Palucka AK, Arce E, Cantrell V, Borvak J, Banchereau J, Pascual V: Interferon and granulopoiesis signatures in systemic lupus erythematosus blood. J Exp Med 2003, 197:711-723.

55. Ramanujam M, Kahn P, Huang W, Tao H, Madaio MP, Factor SM, Davidson A: Interferon-alpha treatment of female (NZW $x$ BXSB)F(1) mice mimics some but not all features associated with the Yaa mutation. Arthritis Rheum 2009, 60:1096-1101.

56. Sharif MN, Tassiulas I, Hu Y, Mecklenbrauker I, Tarakhovsky A, Ivashkiv LB: IFN-alpha priming results in a gain of proinflammatory function by IL-10: implications for systemic lupus erythematosus pathogenesis. J Immunol 2004, 172:6476-6481

57. Hu X, Herrero C, Li WP, Antoniv TT, Falck-Pedersen E, Koch AE, Woods JM, Haines GK, Ivashkiv LB: Sensitization of IFN-gamma Jak-STAT signaling during macrophage activation. Nat Immuno/ 2002, 3:859-866.

58. Triantafyllopoulou A, Franzke C, Seshan S, Perino G, Kalliolias GD, Ramanujam M, van Rooijen N, Davidson A, Ivashkiv LB: Proliferative lesions and metalloproteinase activity in murine lupus nephritis mediated by type I interferons and macrophages. Proc Nalt Acad Sci USA 2010, 107:3012-3017.

59. Fairhurst AM, Xie C, Fu Y, Wang A, Boudreaux C, Zhou XJ, Cibotti R, Coyle A, Connolly JE, Wakeland EK, Mohan C: Type I interferons produced by resident renal cells may promote end-organ disease in autoantibodymediated glomerulonephritis. J Immuno/ 2009, 183:6831-6838.

60. van Baarsen LG, van der Pouw Kraan TC, Kragt JJ, Baggen JM, Rustenburg F, Hooper T, Meilof JF, Fero MJ, Dijkstra CD, Polman CH, Verweij CL: A subtype of multiple sclerosis defined by an activated immune defense program. Genes Immun 2006, 7:522-531.

61. Comabella M, Lünemann JD, Río J, Sánchez A, López C, Julià E, Fernández M Nonell L, Camiña-Tato M, Deisenhammer F, Caballero E, Tortola MT, Prinz M, Montalban X, Martin R: A type I interferon signature in monocytes is associated with poor response to interferon-beta in multiple sclerosis. Brain 2009, 132(Pt 12):3353-3365.

62. van der Pouw Kraan TC, Wijbrandts CA, van Baarsen LG, Voskuyl AE, Rustenburg F, Baggen JM, Ibrahim SM, Fero M, Dijkmans BA, Tak PP, Verweij $\mathrm{CL}$ : Rheumatoid arthritis subtypes identified by genomic profiling of peripheral blood cells: assignment of a type I interferon signature in a subpopulation of patients. Ann Rheum Dis 2007, 66:1008-1014.

63. Adriaansen J, Fallaux FJ, de Cortie CJ, Vervoordeldonk MJ, Tak PP: Local delivery of beta interferon using an adeno-associated virus type 5 effectively inhibits adjuvant arthritis in rats. J Gen Virol 2007, 88(Pt 6):1717-1721.

64. Adriaansen J, Kuhlman RR, van Holten J, Kaynor C, Vervoordeldonk MJ, Tak PP: Intraarticular interferon-beta gene therapy ameliorates adjuvant arthritis in rats. Hum Gene Ther 2006, 17:985-996.
65. Treschow AP, Teige I, Nandakumar KS, Holmdahl R, Issazadeh-Navikas S: Stromal cells and osteoclasts are responsible for exacerbated collageninduced arthritis in interferon-beta-deficient mice. Arthritis Rheum 2005 52:3739-3748

66. Guo B, Chang EY, Cheng G: The type I IFN induction pathway constrains Th17-mediated autoimmune inflammation in mice. J Clin Invest 2008, 118:1680-1690.

67. Shinohara ML, Kim JH, Garcia VA, Cantor H: Engagement of the type I interferon receptor on dendritic cells inhibits T helper 17 cell development: role of intracellular osteopontin. Immunity 2008, 29:68-78.

68. Sharif MN, Sosic D, Rothlin CV, Kelly E, Lemke G, Olson EN, Ivashkiv LB: Twist mediates suppression of inflammation by type I IFNs and Axl. J Exp Med 2006, 203:1891-1901.

69. Rothlin CV, Ghosh S, Zuniga El, Oldstone MB, Lemke G: TAM receptors are pleiotropic inhibitors of the innate immune response. Cell 2007, 131:1124-1136.

70. Sauer I, Schaljo B, Vogl C, Gattermeier I, Kolbe T, Muller M, Blackshear PJ, Kovarik P: Interferons limit inflammatory responses by induction of tristetraprolin. Blood 2006, 107:4790-4797.

71. Hu X, Ho HH, Lou O, Hidaka C, Ivashkiv LB: Homeostatic role of interferons conferred by inhibition of IL-1-mediated inflammation and tissue destruction. J/mmuno/ 2005, 175:131-138.

72. Molnarfi N, Hyka-Nouspikel N, Gruaz L, Dayer JM, Burger D: The production of IL-1 receptor antagonist in IFN-beta-stimulated human monocytes depends on the activation of phosphatidylinositol 3-kinase but not of STAT1. J Immuno/ 2005, 174:2974-2980.

73. Harrington LE, Hatton RD, Mangan PR, Turner H, Murphy TL, Murphy KM, Weaver CT: Interleukin 17-producing $\mathrm{CD}^{+}$effector T cells develop via a lineage distinct from the Thelper type 1 and 2 lineages. Nat Immuno/ 2005, 6:1123-1132

74. Zhang X, Jin J, Tang Y, Speer D, Sujkowska D, Markovic-Plese S: IFN- $\beta 1$ inhibits the secretion of Th17-polarizing cytokines in human dendritic cells via TLR7 up-regulation. J Immuno/ 2009, 182:3928-3936.

75. Ramgolam VS, Sha Y, Jin J, Zhang X, Markovic-Plese S: IFN-beta inhibits human Th17 cell differentiation. J Immuno/ 2009, 183:5418-5427.

76. Indraccolo S, Pfeffer U, Minuzzo S, Esposito G, Roni V, Mandruzzato S, Ferrari N, Anfosso L, Dell'Eva R, Noonan DM, Chieco-Bianchi L, Albini A, Amadori A: Identification of genes selectively regulated by IFNs in endothelial cells. J Immunol 2007, 178:1122-1135.

77. Denny MF, Thacker S, Mehta H, Somers EC, Dodick T, Barrat FJ, McCune WJ, Kaplan MJ: Interferon-alpha promotes abnormal vasculogenesis in lupus: a potential pathway for premature atherosclerosis. Blood 2007 110:2907-2915.

78. Tassiulas I, Hu X, Ho H, Kashyap Y, Paik P, Hu Y, Lowell CA, Ivashkiv LB: Amplification of IFN-alpha-induced STAT1 activation and inflammatory function by Syk and ITAM-containing adaptors. Nat Immuno/ 2004 , 5:1181-1189.

79. Nguyen KB, Watford WT, Salomon R, Hofmann SR, Pien GC, Morinobu A, Gadina M, O'Shea JJ, Biron CA: Critical role for STAT4 activation by type 1 interferons in the interferon-gamma response to viral infection. Science 2002, 297:2063-2066.

doi:10.1186/ar288

Cite this article as: Kalliolias GD, Ivashkiv LB: Overview of the biology of type I interferons. Arthritis Research \& Therapy 2010, 12(Suppl 1):S1. 